\title{
Sluggish and Brisk Ganglion Cells Detect Contrast With Similar Sensitivity
}

\author{
Ying Xu, Narender K. Dhingra, Robert G. Smith, and Peter Sterling \\ Department of Neuroscience, University of Pennsylvania, Philadelphia, Pennsylvania
}

Submitted 15 October 2004; accepted in final form 13 December 2004

Xu, Ying, Narender K. Dhingra, Robert G. Smith, and Peter Sterling. Sluggish and brisk ganglion cells detect contrast with similar sensitivity. J Neurophysiol 93: 2388-2395, 2005. First published December 15, 2004; doi:10.1152/jn.01088.2004. Roughly half of all ganglion cells in mammalian retina belong to the broad class, termed "sluggish." Many of these cells have small receptive fields and project via lateral geniculate nuclei to visual cortex. However, their possible contributions to perception have been largely ignored because sluggish cells seem to respond weakly compared with the more easily studied "brisk" cells. By selecting small somas under infrared DIC optics and recording with a loose seal, we could routinely isolate sluggish cells. When a spot was matched spatially and temporally to the receptive field center, most sluggish cells could detect the same low contrasts as brisk cells. Detection thresholds for the two groups determined by an "ideal observer" were similar: threshold contrast for sluggish cells was $4.7 \pm 0.5 \%$ (mean $\pm \mathrm{SE}$ ), and for brisk cells was $3.4 \pm 0.3 \%$ (Mann-Whitney test: $P>0.05$ ). Signal-to-noise ratios for the two classes were also similar at low contrast. However, sluggish cells saturated at somewhat lower contrasts (contrast for half-maximum response was $14 \pm 1$ vs. $19 \pm 2 \%$ for brisk cells) and were less sensitive to higher temporal frequencies (when the stimulus frequency was increased from 2 to $4 \mathrm{~Hz}$, the response rate fell by 1.6 -fold). Thus the sluggish cells covered a narrower dynamic range and a narrower temporal bandwidth, consistent with their reported lower information rates. Because information per spike is greater at lower firing rates, sluggish cells may represent "cheaper" channels that convey less urgent visual information at a lower energy cost.

\section{N T R O D U C T I O N}

The best-studied ganglion cells in mammalian retina are classified as "brisk" because they respond rapidly at stimulus onset with relatively high firing rates (Cleland and Levick 1974a; Stone and Fukuda 1974). Brisk cells are broadly tuned to spatiotemporal features of the stimulus, and they are highly sensitive to stimulus contrast; for example, the most sensitive ones can detect a spot over the receptive field center when contrast is as low as 0.5\% (Dhingra and Smith 2004; Dhingra et al. 2003; Linsenmeier et al. 1982). But brisk cells constitute only half of the population (Rowe and Palmer 1994; Troy and Shou 2002; Wässle and Boycott 1991).

The rest can be classified as "sluggish" because they respond slowly at stimulus onset with low peak firing rates (Amthor et al. 1989; Caldwell and Daw 1978; Cleland and Levick 1974a,b). Sluggish cells can be quite selective for particular spatial and temporal features of the stimulus, such as local edge, slow motion, or motion in a particular direction (Levick 1967; Rowe and Cox 1993; Stone and Fukuda 1974; Troy and Shou 2002). These properties, which arise from strong inhib-

Address for reprint requests and other correspondence: Y. Xu, 123 Anatomy/Chemistry Bldg., Dept. of Neuroscience, University of Pennsylvania School of Medicine, Philadelphia, PA, 19104-6058 (E-mail: ying@retina.anatomy.upenn.edu). itory mechanisms (Caldwell et al. 1978), combine to make sluggish cells hard to "drive," and this led us to wonder if they are fundamentally less sensitive than brisk cells.

This question seemed worth tackling for two reasons. First, although sluggish cells innervate brain stem structures, such as accessory optic and pretectal nuclei, and superior colliculus, they also innervate thalamic nuclei that project to striate and extrastriate cortex (Dacey et al. 2003; Troy and Shou 2002; Van Hooser et al. 2003; Wilson and Stone 1975). Thus sluggish cells probably affect high level processes related to perception. Second, sluggish cells apparently receive far fewer excitatory synapses than brisk cells and relatively more inhibitory inputs (Kolb 1979; Watanabe et al. 1985). Therefore to establish the relative sensitivities of brisk and sluggish cells should help clarify how sensitivity emerges from the balance of excitation and inhibition.

Sluggish cells are hard to record in vivo because their somas are small and their axons are fine. However, in vitro they are easier to record because a soma can be visualized with DIC optics and then attached stably to a loose-patch electrode (Koch et al. 2004). This approach, also used here, begins to restore the balance of knowledge between the brisk and sluggish components of the optic nerve.

\section{METHODS}

\section{Tissue preparation and recording}

An adult guinea pig was anesthetized with ketamine $(100 \mathrm{mg} / \mathrm{kg})$, xylazine $(20 \mathrm{mg} / \mathrm{kg})$, and pentobarbital $(50 \mathrm{mg} / \mathrm{kg})$. Then an eye was removed, and the animal was killed by overdose of pentobarbital (100 $\mathrm{mg} / \mathrm{kg}$ ). The retina, attached to the pigment epithelium, choroid and sclera, was incised radially and flattened with ganglion cells up on a membrane filter in oxygenated $\left(95 \% \mathrm{O}_{2}-5 \% \mathrm{CO}_{2}\right)$ Ames medium (Sigma, St. Louis, MO) containing sodium bicarbonate $(1.9 \mathrm{~g} / \mathrm{l})$ and glucose $(0.8 \mathrm{~g} / \mathrm{l})$. After resting in darkness for about half an hour, the retina was mounted in a chamber on a microscope stage and superfused with oxygenated Ames medium (4-8 $\mathrm{ml} / \mathrm{min}, 34-36^{\circ} \mathrm{C}$ ).

A ganglion cell soma from the visual streak was selected under infrared DIC optics and cleared of Muller cell end-feet by squirting Ames medium from a pipette under mild pressure. A glass pipette (tip resistance: 3-4 M 2 ) was then attached loosely by mild suction. Spikes were amplified (Neurodata IR-283, Cygnus Technologies, Delaware Water Gap, PA), high-pass filtered at $100 \mathrm{~Hz}$, and sampled at $5 \mathrm{kHz}$ by Axoscope software (Axon Instruments, Foster City, CA). Sometimes after recordings, we replaced the patch pipette with a sharp electrode, injected DiI (2\%, Molecular Probes, Eugene, OR) and subsequently imaged the cell with a confocal microscope.

The costs of publication of this article were defrayed in part by the payment of page charges. The article must therefore be hereby marked "advertisement" in accordance with 18 U.S.C. Section 1734 solely to indicate this fact. 


\section{Visual stimulation}

Visual stimuli were generated with Matlab (MathWorks, Natick, $\mathrm{MA})$ and displayed on a miniature monochrome computer monitor $(640 \times 480$ pixels, $60 \mathrm{~Hz})$ (Lucivid MR1-103, Microbrightfield, Colchester, VT) projected through a $4 \times$ objective and focused on the photoreceptors. Mean background intensity was 7,900 photons $/ \mu \mathrm{m}^{2} / \mathrm{s}$, (equivalent to $\sim 2 \times 10^{4} \mathrm{R} * /$ cone/s or $\sim 0.6 \times 10^{4} \mathrm{R} * / \mathrm{rod} / \mathrm{s}$ at 535 $\mathrm{nm})$, well into the photopic range. The relation between gun voltage and monitor intensity was linearized in software with a lookup table. Contrast was defined as $\left(I_{\text {max }}-I_{\text {mean }}\right) / I_{\text {mean }}$, where $I_{\text {mean }}=$ $\left[d^{*} I_{\max }+(1-d)^{*} I_{\min }\right]$, where $I_{\max }$ and $I_{\min }$ are the maximum and minimum light intensities and $d$ is the duty cycle. The stimulus was a spot of variable size, duration, temporal frequency, and contrast. Typically the spot was a $100-$ or $250-\mathrm{ms}$ square-wave repeated at $0.5-4 \mathrm{~Hz}$, and for the remainder of the cycle, the mean background intensity was presented. At $2 \mathrm{~Hz}$, the 100-ms square wave constituted a duty cycle of $20 \%$. For contrast threshold measurements, an ideal observer analyzed the responses within the whole cycle. When testing a cell's temporal frequency tuning, we used a moderate contrast $(10-20 \%)$ sine-wave-modulated spot with $50 \%$ duty cycle, and the response was measured as the first harmonic component (F1) because this component was the largest one among other components that originated in nonlinearities and most nonlinear cells gave half-wave rectified responses to sine-wave stimuli.

To measure the time course of the mean effective stimulus, a random flickering checkerboard was presented to the retina. The checkerboard consisted of at least $5 \times 5$ squares with a size of $10 \times$ 10 to $50 \times 50 \mu \mathrm{m}$ each, where the central one matched the receptive field center of the cell. Each of the squares changed its intensity independently according to a pseudorandom sequence at a frequency of $30 \mathrm{~Hz}$. Then the sequence of patterns was cross-correlated with the cell's spike response to obtain the mean effective stimulus for this cell (Figs. $1 D$ and $6 A$ ). Temporal bandwidths of this cell were calculated from the Fourier-transform of the time course to produce the power spectra (Fig. 6B).

\section{Ideal observer analysis}

To determine a cell's threshold for contrast detection, we constructed an ideal observer using a single-interval two-alternative forced-choice paradigm (Dhingra et al. 2003; Geisler et al. 1991). Responses were recorded to 100-200 repeated presentations of several contrasts between 0 and $30 \%$. A given contrast was presented in blocks of 10-40 trials, which were interleaved with similar blocks at other contrasts in pseudorandom order. To reduce the effect of adaptation, blocks were interleaved with $5 \mathrm{~s}$ of mean background, and the first trial in each block was discarded.

Half of the responses (randomly chosen) at a given contrast were used to construct a histogram that was normalized to create a probability density function (PDF). Separate functions were constructed for each stimulus. Then the ideal observer was presented the remaining responses individually and decided for each response which of the two stimuli (a nonzero contrast stimulus vs. $0 \%$ or mean background) had most likely been presented. Because it was impractical to collect a sufficient amount of data to construct the ideal observer using a multidimensional histogram, we approximated the ideal observer with unidimensional histograms based on the temporal pattern of the spike trains. This method is more sensitive than one based on total spike count because it emphasizes the time bins that contain the most information (Dhingra et al. 2003). The responses at each contrast were divided into temporal bins ( $40 \mathrm{~ms}$ ), and the probability of 0 to $n$ spikes was calculated for each bin. The spike pattern was obtained by multiplying the PDFs of all bins to give their joint probability. Then ideal observer made a choice by computing the likelihood ratio (Geisler et al. 1991) given by

$$
L=\prod_{i=1}^{n} P_{i}\left(N_{i} / B\right) / \prod_{i=1}^{n} P_{i}\left(N_{i} / A\right)
$$

where $N_{i}$ is the number of spikes in $i$ th bin, and $n$ is the number of temporal bins, and $A$ and $B$ are the two stimuli (Dhingra et al. 2003). When $L>1$, the ideal observer chose stimulus $B$; for $L<1$, it chose stimulus $A$. For some analyses, we did not compute the joint probability but instead compared PDFs from single bins (Fig. 4D). The likelihood ratio computed in this way, because it was not an approximation, was optimal (Dhingra and Smith 2004; Geisler et al. 1991). When the choice corresponded to the stimulus that had actually been presented, it was "correct." A neurometric function was defined as the fraction of correct responses versus contrast and fitted with a cumulative Weibull function (Quick 1974; Weibull 1951) (Fig. 4B) as follows

$$
P=1-0.5 \exp \left(-(C / \alpha)^{\beta}\right)
$$

where $P$ is the probability of correct choices, $C$ is the contrast, $\alpha$ is the threshold and $\beta$ is the slope of the Weibull function. Threshold was defined as the contrast that gave $68 \%$ correct choices (Dhingra et al. 2003; Geisler et al. 1991).

\section{Signal and noise from contrast response function}

To understand the contrast detection thresholds in terms of signalto-noise ratio, signal and noise were measured for each cell at different contrasts ranging from 0 to $100 \%$. The signal was defined as the average evoked spike frequency summed over all trials (20-40 trials) within the single time bin $(40 \mathrm{~ms})$ containing the peak firing rate. Noise was defined as the SD of the response frequency in that bin across trials.

Although the noise computed by this method could be reduced by summing over more time bins, this would also decrease the signal. An attempt to generate an ideal filter to weight each time bin did not provide a better estimate of signal and noise because the response wave shape varied with contrast. Furthermore, because the number of trials we tested (20-40) in this series of experiments was limited, it was not possible to create a reliable estimate of the ideal temporal pattern to weight each time bin before summing them. Thus as a compromise, we choose a single bin.

The signal and noise responses versus contrast were fitted with a modified Naka-Rushton equation (Boynton et al. 1999; Dhingra and Smith 2004; Naka and Rushton 1966) as

$$
R(C)=R_{\max } *\left(C^{p+q} /\left(C^{q}+\sigma^{q}\right)-T\right)
$$

where $R$ is the response, $C$ is the stimulus contrast, and the other symbols determine the shape of contrast-response function. Increment thresholds were estimated from signal and noise measurements by assuming that at any contrast the minimum discriminable contrast increment was proportional to the noise in the response measured at that contrast (Dhingra and Smith 2004).

Unless stated otherwise, we applied the nonparametric, MannWhitney test for statistical comparison.

\section{RES U L T S}

We studied 45 ganglion cells from the visual streak of 19 animals. Twenty-four cells responded briskly, firing at short latency and relatively high rates. Among them, brisk-transient cells $(n=14)$ resembled the Y/alpha cells in cat and rabbit, with large somas, broad dendritic fields, and broad receptive field centers with modest surround antagonism (Fig. 1). They responded well to stimuli $>4 \mathrm{~Hz}$. Brisk-sustained cells $(n=10)$ resembled $\mathrm{X} /$ beta cells in cat and rabbit with medium somas and medium dendritic fields. They resembled 

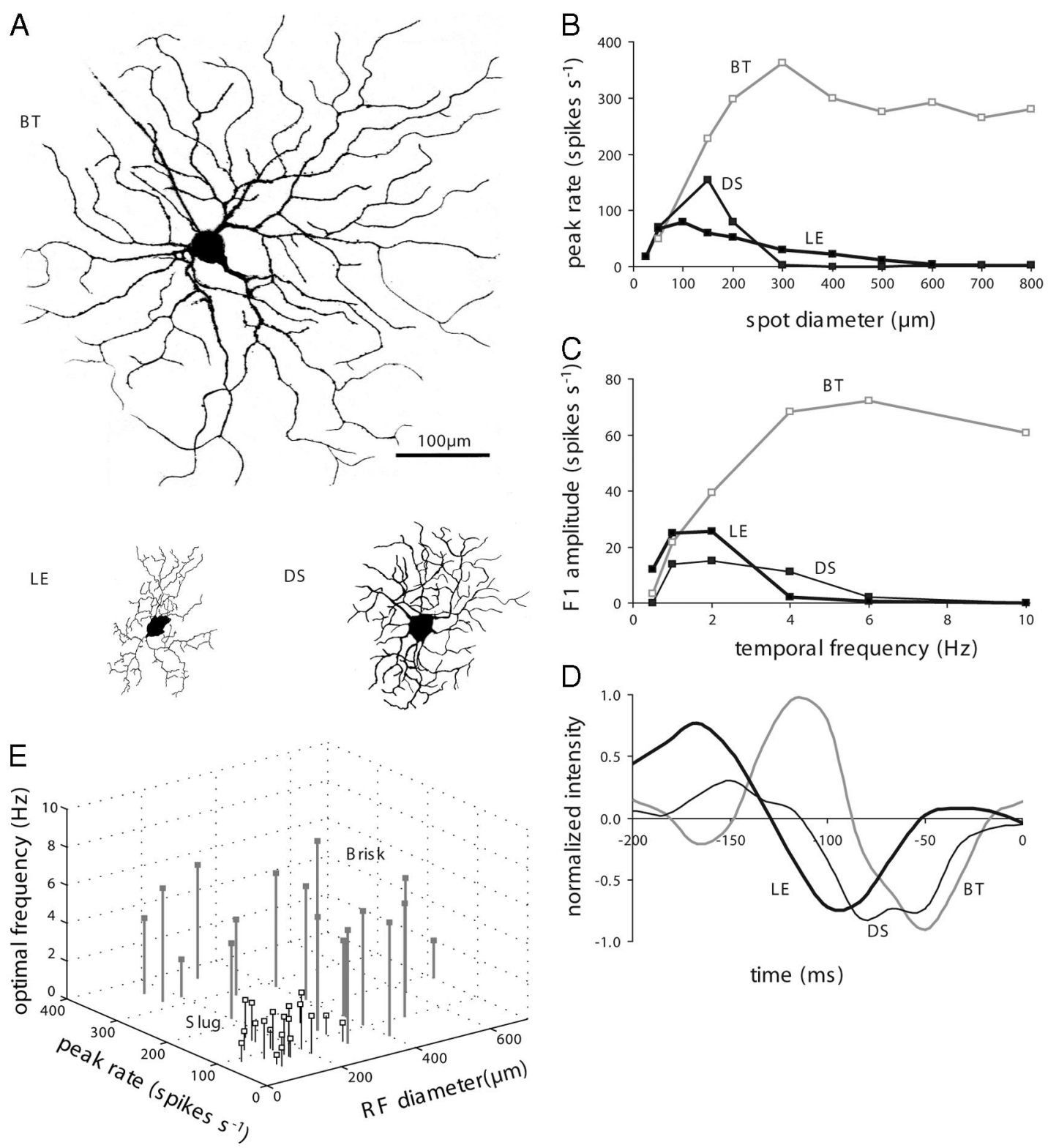

time (ms)

FIG. 1. Identifying brisk and sluggish ganglion cells. A: each cell type expressed a distinctive morphology. Brisk-transient cell (BT) had a large soma and broad dendritic field. Sluggish cells, here a local-edge cell (LE) and an ON-OFF directionally selective cell (DS), had smaller somas and much narrower dendritic fields. All cells were located in the visual streak. B: sluggish cells fired at lower rates. Stimulus was a high contrast (50\%) square-wave spot filling the receptive field center. $C$ : sluggish cells responded at lower temporal frequencies. Stimulus was a sinusoidally modulated spot at $10 \%$ contrast. Ordinate: amplitude of the 1 st harmonic responses (F1). D: time courses of mean effective stimulus for the 3 cells showed a longer time-to-peak for the 2 sluggish cells. The mean effective stimulus was obtained by cross-correlating a quasi-random stimulus sequence ("flickering checkerboard") with each spike in a cell's response (see METHODS). $E$ : sluggish cells and brisk cells formed distinct clusters in a multiparametric space constructed from peak firing rate, size of receptive field, and optimal frequency.

brisk-transient cells in latency, peak rates, and temporal sensitivity.

Twenty-one cells responded sluggishly, firing with long latency (Figs. $1 D$ and $6 A$ ) and relatively low rates (Fig. $1 B$ ). Many of these cells had small somas, narrow dendritic fields, and narrow receptive field centers with strong surround antagonism, which resembled "W" cells in cat and rabbit (Amthor et al. 1989; Row and Cox 1993; Troy and Shou 2002). They responded best to stimuli $\sim 1-2 \mathrm{~Hz}$ and hardly responded to stimuli $>4 \mathrm{~Hz}$ (Fig. 1C). Thus considering three parameters: peak firing rate, optimal temporal frequency, and receptive field size, sluggish and brisk cells formed distinct clusters in multi-parametric space (Fig. 1E). The plot illustrates that no single parameter could separate brisk from sluggish cells, but the three parameters together clearly separated the tight sluggish cluster from the brisk cluster.

Sluggish cells comprise more than seven types (Troy and Shou 2002), and we could identify several of them. For example, the local-edge cell had a narrow receptive field center, strong suppressive surround, and narrow dendritic field that stratified narrowly at mid-level of the inner plexiform layer (Fig. 1). Similarly, the ON-OFF DS cell was directionally sensitive with a medium dendritic field that stratified in both on and OFF levels of the inner plexiform layer (Fig. 1). Our sample of 

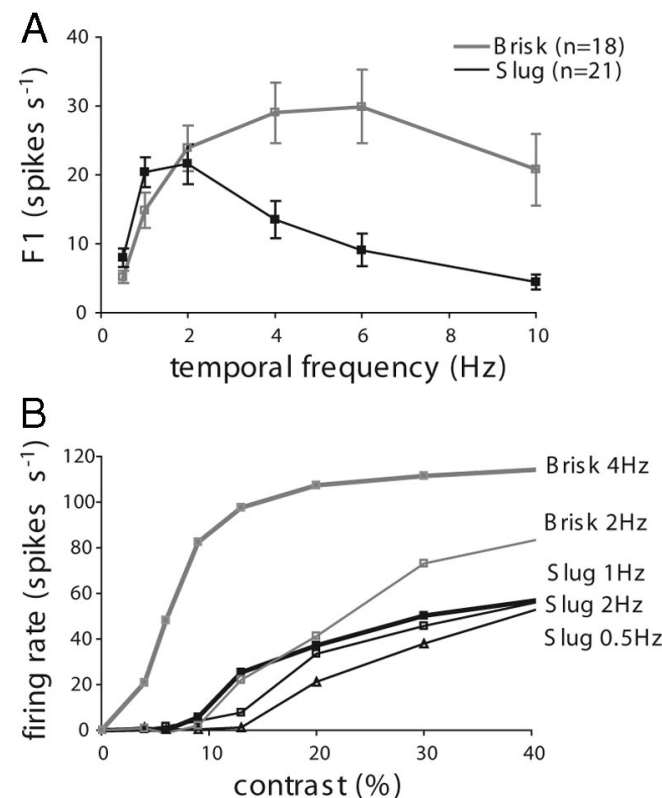

FIG. 2. Optimize temporal frequencies for sluggish and brisk cells. A: mean temporal tuning curves for sluggish and brisk cells. The optimal frequency for the sluggish cells was 1 or $2 \mathrm{~Hz}$, whereas that for brisk cells was $\sim 4 \mathrm{~Hz}$ or even higher. $B$ : stimulus at $4 \mathrm{~Hz}$ elicited stronger response thus higher contrast sensitivity for a brisk cell than at $2 \mathrm{~Hz}$, whereas a sluggish cell was more sensitive to a stimulus at $1 \mathrm{~Hz}$ than either 2 or $0.5 \mathrm{~Hz}$.

sluggish cells was too small to evaluate the sensitivity of all the types, but within the group, we found no obvious differences in contrast sensitivity.

\section{Optimizing the stimulus and the ideal observer}

Before measuring a cell's contrast threshold, we first determined the optimal spot size and temporal frequency. Brisk and sluggish cells preferred different temporal frequencies (Fig. $2 A$ ) which affected their spike responses and contrast sensitivities (Fig. 2B). The optimal temporal frequency for sluggish cells was $<2 \mathrm{~Hz}$, whereas for brisk cells it was $4 \mathrm{~Hz}$ or in some cases slightly higher. Using this estimation procedure, we selected the repetition rate used in each square wave spot experiment, typically 2 or $4 \mathrm{~Hz}$ for brisk cells and 1 or $2 \mathrm{~Hz}$ for sluggish cells (Fig. 2). More than $4 \mathrm{~Hz}$, the brisk cells' response to the stimulus flash did not recover to baseline completely between stimuli. Less than $1 \mathrm{~Hz}$, sluggish cells responded well, but the longer inter-trial intervals restricted the number of responses that could be collected. Stimulus duration was $100 \mathrm{~ms}$ for brisk cells (Dhingra et al., 2003) and usually 100 or $250 \mathrm{~ms}$ for sluggish cells; prolonging the stimulus to $400 \mathrm{~ms}$ gave no improvement.

With the stimulus optimized, we presented a cell with 100-200 trials of this optimal square-wave spot at 6-10 contrasts (Fig. 3), in a session extending over 60 min. Stability of the cell was checked by measuring the contrast response function before and after these measurements.

We directed the ideal observer to evaluate the temporal pattern of spikes because this gives the lowest threshold (Dhingra et al. 2003). Because bin width would affect the performance of the ideal observer, we tested bin widths between 10 and $200 \mathrm{~ms}$. For brisk cells, thresholds were generally lowest with a 40-ms bin (confirming Dhingra et al. 2003); for sluggish cells, thresholds were insensitive to the bin widths tested, so for all cells we report their responses in 40-ms bins.

\section{Contrast thresholds}

Contrasts greater than $\sim 10 \%$ evoked much stronger responses in brisk than in sluggish cells, but contrasts less than $\sim 10 \%$ evoked similar responses in both classes. Because detection thresholds were mainly determined by the weakest responses, both cell classes had similar thresholds. This feature, shown for a brisk and sluggish pair in Fig. 3, was also characteristic for the two populations: different mean response at high contrast, but similar responses at low contrast, thus similar contrast thresholds (Fig. 4, $A$ and $B$ ).

The mean detection threshold for brisk cells was $3.4 \pm 0.3 \%$ (mean $\pm \mathrm{SE}, n=24$ ), and for sluggish cells it was $4.7 \pm 0.5 \%$ ( $n=19$; Fig. 4). The difference was slight and insignificant
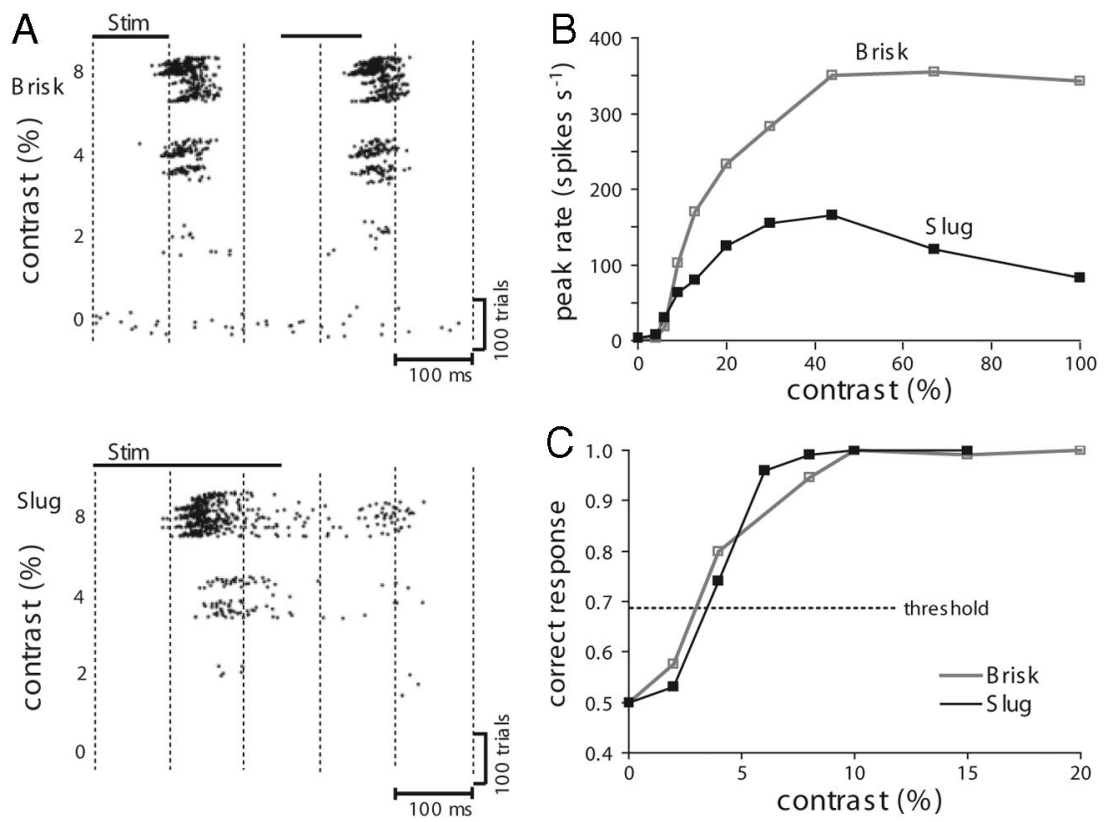

FIG. 3. Sluggish cell showed lower gain than brisk cell but similar threshold for contrast detection. A: spike responses of a brisk and a sluggish cell to 100 trials at each of several contrasts near threshold. Stimulus was presented to the brisk cell at twice the frequency and for a shorter duration than for the sluggish cell. $B$ : below $\sim 10 \%$ contrast, evoked responses were similar for the sluggish and brisk cells, rising sharply with high gain. At higher contrasts the brisk cell's response continued to rise and saturated $\sim 45 \%$, whereas the sluggish cell's response rose more slowly and saturated earlier, at $\sim 30 \%$. C: contrast detection threshold was determined by an ideal observer using all the information available in the temporal pattern of spiking (see METHODS). Thresholds for these 2 cells were nearly identical. 

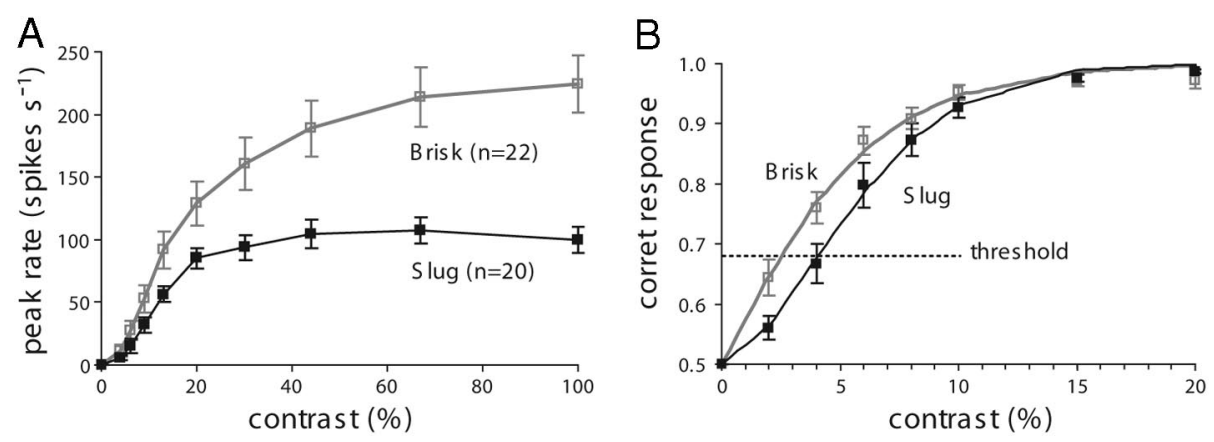

FIG. 4. Contrast sensitivity functions and detection thresholds for sluggish and brisk populations. A: sluggish cell responses to contrast rose more slowly and saturated earlier. Vertical bars, SE. $B$ : sluggish and brisk detection thresh-
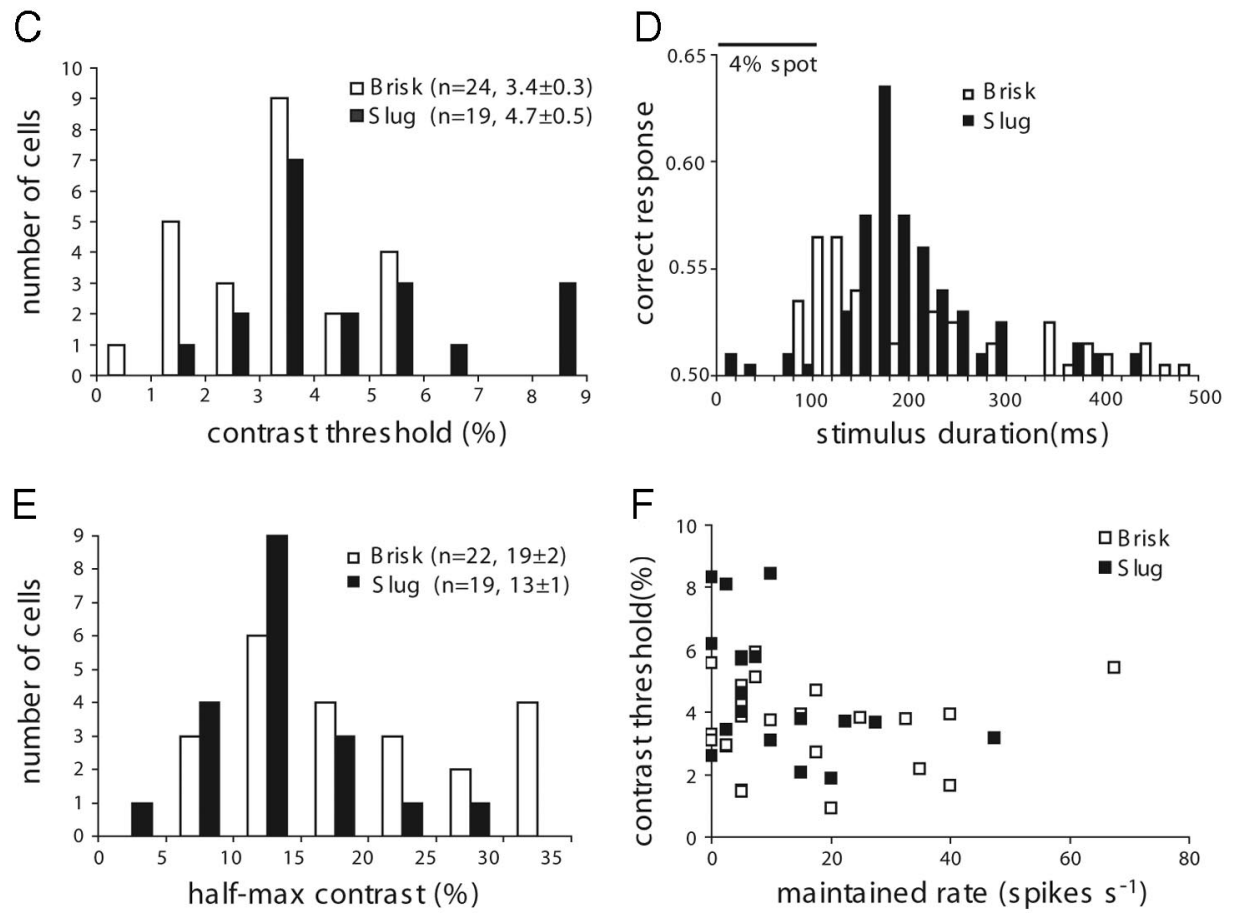
olds were similar. The fraction of correct responses vs. contrast was fitted with cumulative Weibull function (Eq. 2) for the averaged values across cells. $C$ : most sluggish cells $(>85 \%)$ showed detection thresholds between 1.8 and $5.8 \%$, and this range was bracketed by the brisk cells $(0.9-5.9 \%)$. The population means did not differ significantly. $D$ : sluggish cell detection sensitivity during the stimulus cycle $(4 \%$ square-wave spot, near threshold for this pair of cells) peaked $\sim 60 \mathrm{~ms}$ later than for brisk cells. Each bar represents the cell's ideal performance for 1 time bin $(20 \mathrm{~ms})$, see METHODS. $E$ : distribution of contrasts that gave half-maximal response overlapped for sluggish and brisk cells, but the population means differed $(P<0.05)$ because brisk cells tended to saturate at higher contrasts. $F$ : contrast detection thresholds were uncorrelated with maintained rate.

( $P>0.05$, Mann-Whitney test). Furthermore, more than onethird of the cells in each class had thresholds between 3 and $4 \%$, and $\sim 85 \%$ of sluggish cells shared the same range of thresholds as brisk cells (1-6\%, Fig. 4C). Thus we conclude that contrast detection thresholds for the two broad classes are, if not identical, certainly close.

Within the brisk category, brisk-transient (BT) had similar contrast thresholds as brisk-sustained (BS) cells (BT: $3.2 \pm 0.4 \%, n=14$; BS: $3.6 \pm 0.3 \%, n=10 ; P>0.4$ ) (see Kaplan and Shapley 1982, 1986; Troy 1983). Within the sluggish category, two local-edge cells and one oN-sustained sluggish cell showed unusually low sensitivity (thresholds $>6 \%$ ), but other cells of the same types were found to be more sensitive. For the five local-edge cells recorded, their thresholds ranged between 3.8 and $8.4 \%$, the mean value $(6.4 \pm 0.9 \%)$ was not significantly different from five ON-OFF DS cells $(4.0 \pm 0.5 \%, P>0.05)$. Other types of sluggish cell were too sparsely represented in our sample to allow meaningful comparison.

To understand how a neuron's ideal performance varied in time, we measured performance for individual time bins and compared sluggish with brisk cell (Fig. 4D). Performance showed two peaks, a robust one during the initial excitatory phase of the response and a weaker one during the recovery phase. At a near-threshold (4\%) contrast, performance rose slowly then decreased, peaking for a brisk cell at $100 \mathrm{~ms}$ and for a sluggish cell at $160 \mathrm{~ms}$ (Fig. 4D), which corresponded well to the longer response latency of sluggish cell. Furthermore, performance for the sluggish cell in a single time bin was as high as (or even higher than) that for the brisk cell. However, the overall thresholds determined by the joint probability from all the bins were less affected by these differences in the single bin performance. Thus despite their different latencies and peak performance, the thresholds were nearly identical for these two cells (brisk, 3.9\%; sluggish, 4.0\%).

On the other hand, brisk and sluggish cells differed in the dynamic range and slope of their contrast response function. Brisk responses rose faster and saturated at higher contrast (Fig. 4A). For brisk cells the contrast for half-maximum response was $19 \pm 2 \%(n=22)$, and for sluggish cells it was $13 \pm 1 \%(n=19$, Fig. $4 E)$. This difference was significant $(P<0.05)$. For individual cells, contrasts at threshold and at half-maximum response were uncorrelated $(r=0.017, P>$ $0.9, n=41)$.

\section{Contrast threshold versus other response properties}

Contrast thresholds were uncorrelated with either maintained rate $(r=0.01, P=0.95$, Fig. $4 F)$ or peak firing rate 

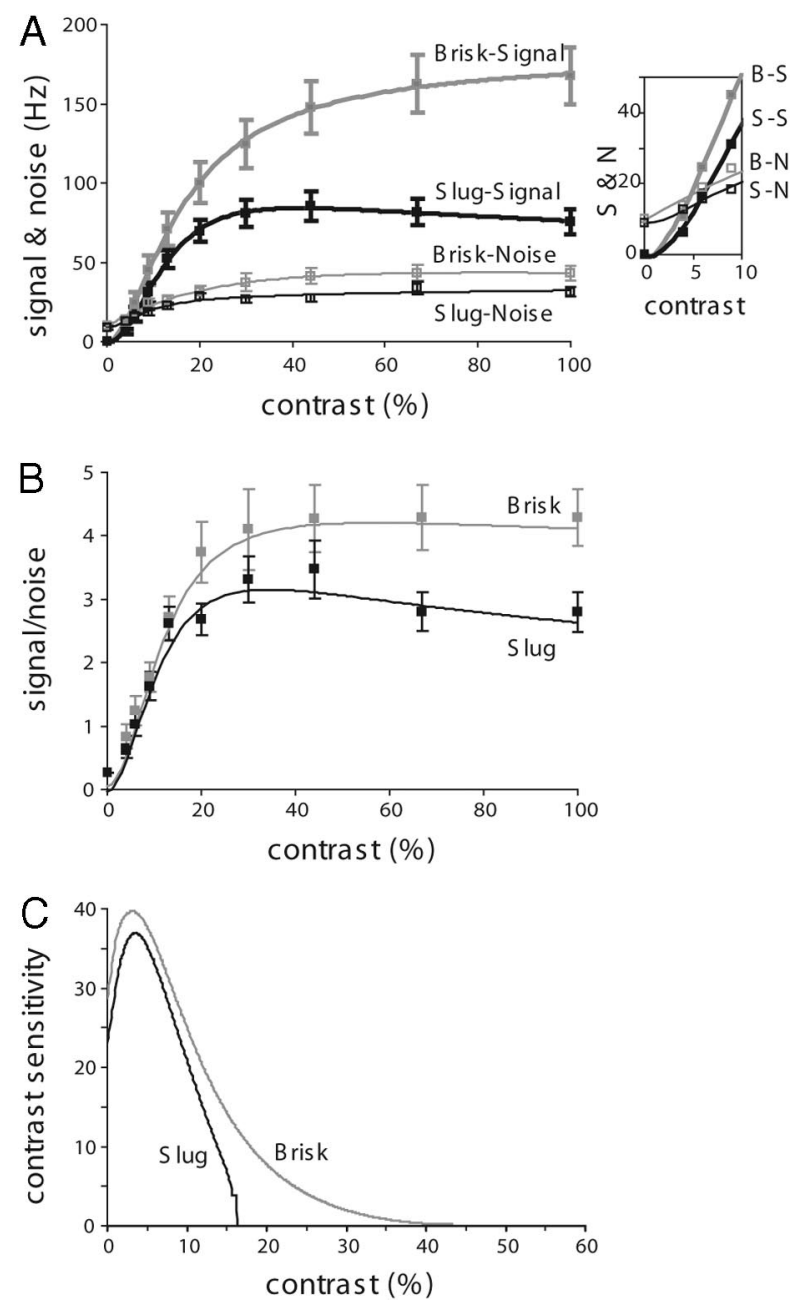

FIG. 5. Similar signal-to-noise ratios and gray levels for sluggish and brisk cells at low contrasts $(<10 \%)$. A: signal and noise were both slightly lower for sluggish cells. Nonlinearities were observed at very low contrast (inset) and high contrast. Signal curves were fitted with $E q$. 3. B: signal-to-noise ratios. At contrasts $<10 \%$, no difference was observed between 2 cell groups, though at higher contrast, brisk cells achieved a greater signal-to-noise ratio. Curves were fitted with $E q$. 3. C: contrast sensitivity, the inverse of the increment threshold estimated from the measured signal and noise curves, showed similar integrated area (gray levels) for brisk and sluggish cells $\leq 10 \%$ contrast (3.4 vs. 3.1). At higher contrasts brisk cells continued to show substantial sensitivity.

$(r=-0.28, P>0.05)$ at high contrast when brisk cells fired more strongly (at $50 \%$ contrast, $209 \pm 20$ vs. $102 \pm 8$ spikes/s for sluggish, $P<0.001$ ). Brisk cells had larger receptive field centers than sluggish cells $(367 \pm 28$ vs. $180 \pm 21 \mu \mathrm{m}, P<$ 0.001 ), but their thresholds were uncorrelated with center $\operatorname{size}(r=0.02, P>0.8)$. Finally, although the optimal temporal frequency was higher for brisk cells than for sluggish (5.2 \pm 0.4 vs. $1.5 \pm 0.2 \mathrm{~Hz}, P<0.001)$, this was uncorrelated with threshold $(n=35, r=-0.32, P>0.05)$.

\section{Signal and noise}

Signal and noise were calculated separately at each contrast (see METHODS, Fig. 5A). Signal increased slowly at very low contrast and then steeply for both brisk and sluggish cells, but this nonlinear behavior was more pronounced for sluggish cells. Both signal and noise amplitudes were consistently lower for sluggish cells, so at low contrast the signal-to-noise ratios were the same for both classes (Fig. $5 B$ ), which contributed to their similar detection thresholds. At higher contrasts $(>20 \%)$, signal-to-noise ratios for brisk cells improved relative to sluggish cells, and the difference was greatest for contrasts above 60\% $(P<0.05)$, as shown in Fig. $5 B$.

We calculated contrast sensitivity (Fig. $5 C$ ) by inverting the increment thresholds estimated from the signal and noise measurements (see METHODs; also Dhingra and Smith 2004). Contrast sensitivity of the brisk and sluggish groups was quite close at low contrast $(<10 \%)$; sensitivity peaked near $4 \%$ contrast for both groups; and then declined at higher contrasts faster for sluggish cells.

To estimate the total gray levels, we integrated contrast sensitivity over contrast. With a greater sensitivity $>20 \%$ contrast, brisk cells had more gray levels than sluggish (5.5 vs. 3.8). However, within the $0-10 \%$ contrast range, the gray levels were similar for brisk and sluggish (3.4 vs. 3.1).

\section{Temporal bandwidth}

Temporal bandwidths were estimated from the Fourier transform of the mean effective stimulus, testing with flickering checkerboards (Fig. 6, $A$ and $B$ ). Sluggish cells had a longer time to peak and had a lower temporal bandwidth than brisk cells.

The power spectra showed smaller differences in cut-off frequency between the two cell groups than shown in the temporal tuning curves (Fig. 2A), probably because of the different stimuli and contrast used. For temporal tuning curves, a sine-wave spot at $20 \%$ contrast was applied with a sequence of frequencies $\leq 10 \mathrm{~Hz}$; whereas the checkerboards comprised a greater range of frequencies, with contrasts up to $100 \%$. Previous work has shown that optimal frequency increased with contrast (Dhingra et al. 2003), so one would expect the optimal frequency to be closer for the two groups at higher contrast.

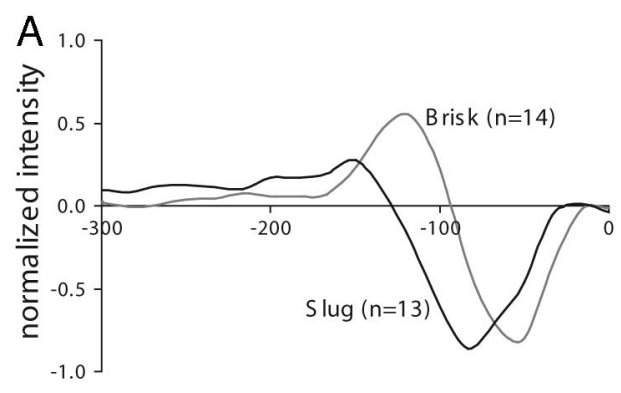

time (ms)

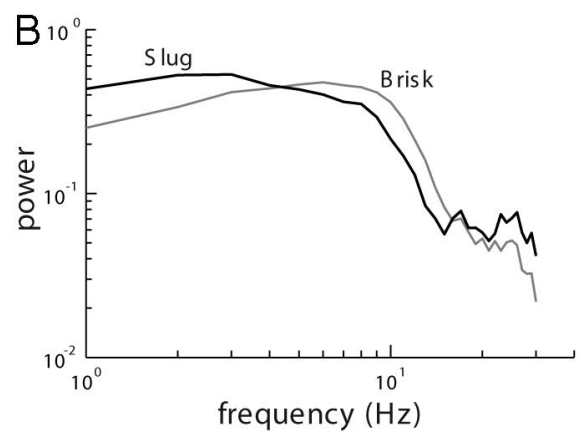

FIG. 6. Sluggish cells transmit at lower bandwidths. A: time course of the mean effective stimulus showed that sluggish cells took longer times to peak and to recovery. The functions for ON cells (4 sluggish cells and 7 brisk cells) were inverted here to combine with OFF cells. $B$ : power spectra (Fourier-transform of the mean effective stimulus) showed lower bandwidth for sluggish cells. 


\section{I S C US S I ON}

Contrast detection thresholds and sensitivities near threshold are similar for brisk and sluggish cells

Our basic finding is that the threshold for detecting an optimal spot is similar for brisk and sluggish cells (3-4\% contrast; Fig. 4). This sensitivity resembles previous studies of brisk-transient cells in the superfused, flat-mounted guinea pig retina (Dhingra et al. 2003) and in vivo measurements in other species (Derrington and Lennie 1982, 1984; Linsenmeier et al. 1982; McCourt and Jacobs 1984). Sensitivity found here for sluggish cells is slightly higher than reported in rabbit by Merwine et al. (1995). Because mammalian species seem to have rather similar sensitivities, the differences in this case may reflect differences in defining threshold and in sensitivity of the preparation.

Contrast gain is reportedly lower for sluggish cells than for brisk (Fig. 4A) (Merwine et al. 1995; Rowe and Cox 1993; Van Hooser et al. 2003). However, this measurement is based on a cell's "responsivity" (spikes/s contrast ${ }^{-1}$ ) and excludes the effect of noise. Although the brisk signal is greater than the sluggish signal, the noise is also larger (Fig. 5A). Therefore despite the many clear differences between brisk and sluggish cells, their detection thresholds are similar $(\sim 4 \%)$, and at low contrasts, the signal-to-noise ratios are similar, as are the numbers of gray levels that they encode (Fig. 5, $B$ and $C$ ).

Initially this seemed puzzling because the sluggish cells probably have far fewer excitatory synapses than brisk cells: the dendritic fields tend to be narrower (Fig. 1A), and the fraction of bipolar (excitatory) inputs seems much lower. For example, in cat, bipolar synapses comprise $40-80 \%$ of input to brisk-sustained cells and $15-50 \%$ for brisk-transient cells, but no more than 20\% for sluggish cells (Cohen and Sterling 1992; Freed and Sterling 1988; Kolb 1979; Watanabe et al. 1985; Weber and Stanford 1994). Our working hypothesis was that a sluggish cell with far fewer excitatory synapses would collect fewer miniature postsynaptic excitatory currents (mEPSCs) with relatively greater Poisson fluctuations than a brisk cell and thus be both absolutely and relatively less sensitive (Croner et al. 1993; Kier et al. 1995).

On the other hand, sluggish cells tend to have higher membrane resistance. For example, for a brisk-transient (alpha) cell input resistance $\left(\mathrm{R}_{\text {in }}\right)$ was $\sim 31 \mathrm{M} \Omega$; whereas for an ON-OFF DS cell (iota), $R_{\text {in }} \sim 396 \mathrm{M} \Omega$, and for a local-edge cell (zeta), $\mathrm{R}_{\text {in }} \sim 1,048 \mathrm{M} \Omega$. (O'Brien et al. 2002). Consequently, in smaller cells the same mEPSC evokes a larger depolarization. The higher membrane resistance also gives the smaller cell a longer time constant, for example, for the brisk-transient, $\tau \sim$ $4.5 \mathrm{~ms}$, for the ON-OFF DS cell, $\tau \sim 36.3 \mathrm{~ms}$, and for the local-edge cell, $\tau \sim 81.6 \mathrm{~ms}$ (O'Brien et al. 2002). The larger depolarization per quantal conductance plus the longer integration time might combine with the biophysical properties that comprise the spike generator (Dhingra and Smith 2004) to render the small cells as sensitive as the large ones. There may be additional factors, such as differences in postsynaptic glutamate receptors (as found for cone input to different bipolar types) (see Devries 2000) and differences in vesicle release rate (as found for output to different ganglion cell types) (see Freed 2000a,b). Finally, the sluggish cells, like the brisk cells, may use synchronous release of synaptic vesicles to minimize the effects of synaptic noise in the spike output (Demb et al. 2004).
One could argue that a simple spot would underestimate contrast sensitivity for cell types selective for specific stimuli, such as direction of motion or local edges, because to such stimuli, the cell type may be more sensitive. However, our purpose in this study was to compare the basic contrast sensitivities of brisk and sluggish cells using a stimulus that synchronously activates all bipolar cells presynaptic to the ganglion cell. Thus our measurements of contrast sensitivity to a spot optimized to fit the receptive field represent a lower bound.

Our measurements also reveal differences between brisk and sluggish cells. With a broader dynamic range and more gray levels, brisk cells can respond more effectively at higher contrasts. Although sluggish cells respond reliably at higher contrasts, their responses saturate $>20 \%$, sacrificing any ability to discriminate between different contrasts.

\section{Why should the retina need multiple pathways of nearly identical sensitivity?}

Despite resembling brisk cells in contrast sensitivity, contrast gain, and number of gray levels at low contrast, sluggish cells express markedly lower peak firing rates. This limits their information rate (bits/s) but increases their spike efficiency (bits/spike) (Koch et al. 2004). Sluggish cells also differ structurally from brisk cells, notably by having much finer axons (reviewed by Troy and Shou 2002). Because the brisk cells cover a broader temporal bandwidth (Fig. 6) and broader dynamic range (Fig. 4), why should the retina expend additional resources on a multiplicity of ganglion cell pathways with low information rates?

In this respect the ganglion cells continue a trend that begins with the photoreceptors and bipolar cells. There, too, are many parallel lines where those with the lowest information rates use the finest axons with the fewest microtubules and the fewest synaptic outputs (Hsu et al. 1998; Sterling 2004). These trends suggest a hypothesis, namely that each channel uses energy in proportion to its information rate (Laughlin et al. 1998). As in daily life, if some messages are important but not urgent, it might be energetically cheaper to send them at a lower rate. Consistent with this, sluggish somas stain weakly for cytochrome oxidase compared with brisk somas (Kageyama and Wong-Riley 1984), although quantitative comparisons for the complete neurons are not available. If this is roughly correct, then the biophysical properties of sluggish cells, which limit the spike rate (O'Brien et al. 2002), and thus the information rate (Koch et al. 2004), offer clear advantages.

\section{A C K N O W LE D G M EN T S}

We thank M. Freed for comments on the manuscript.

\section{G R A N T S}

This work was supported by National Institutes of Health Grants EY-00828 to P. Sterling and MH-48168 to R. G. Smith.

\section{REFERENCES}

Amthor FR, Takahashi ES, and Oyster CW. Morphologies of rabbit retinal ganglion cells with complex receptive fields. J Comp Neurol 280: 97-121, 1989.

Berson DM, Pu M, and Famiglietti EV. The zeta cell: a new ganglion cell type in cat retina. J Comp Neurol 399: 269-288, 1998.

Boynton GM, Demb JB, Glover GH, and Heeger DJ. Neuronal basis of contrast discrimination. Vision Res 39: 257-269, 1999. 
Caldwell JH and Daw NW. New properties of rabbit retinal ganglion cells. J Physiol 276: 257-276, 1978.

Caldwell JH, Daw NW, and Wyatt HJ. Effects of picrotoxin and strychnine on rabbit retinal ganglion cells: lateral interactions for cells with more complex receptive fields. J Physiol 276: 277-298, 1978.

Cleland BG and Levick WR. Brisk and sluggish concentrically organized ganglion cells in the cat's retina. $J$ Physiol 240: 421-456, 1974a.

Cleland BG and Levick WR. Properties of rarely encountered types of ganglion cells in the cat's retina and an overall classification. J Physiol 240: 457-492, 1974b.

Cohen E and Sterling P. Parallel circuits from cones to the on-beta ganglion cell. E J Neurosci 4: 506-520, 1992.

Croner LJ, Purpura K, and Kaplan E. Response variability in retinal ganglion cells of primates. Proc Natl Acad Sci USA 90: 8128-8130, 1993.

Dacey DM, Peterson BB, Robinson FR, and Gamlin PD. Fireworks in the primate retina: neurotechnique in vitro photodynamics reveals diverse LGNprojecting ganglion cell types. Neuron 37: 15-27, 2003.

Demb JB, Sterling P, and Freed MA. How retinal ganglion cells prevent synaptic noise from reaching the spike output. J Neurophysiol 92: 25102519, 2004.

Derrington AM and Lennie P. The influence of temporal frequency and adaptation level on receptive field organization of retinal ganglion cells in cat. J Physiol 333: 343-366, 1982.

Derrington AM and Lennie P. Spatial and temporal contrast sensitivities of neurons in lateral geniculate neucleus of macaque. J Physiol 357: 219-240, 1984.

Devries SH. Bipolar cells use kainate and AMPA receptors to filter visual information into separate channels. Neuron 28: 847-856, 2000.

Devries SH and Baylor DA. Mosaic arrangement of ganglion cell receptive fields in rabbit retina. J Neurophysiol 78: 2048-2060, 1997.

Dhingra NK, Kao YH, Sterling P, and Smith RG. Contrast thresholds of a brisk-transient ganglion cell in vitro. J Neurophysiol 89: 2360-2369, 2003.

Dhingra NK and Smith RG. Spike generator limits efficiency of information transfer in a retinal ganglion cell. J Neurosci 24: 2914-2922, 2004.

Freed MA. Parallel cone bipolar pathways to a ganglion cell use different rates and amplitudes of quantal excitation. J Neurosci 20: 3956-3963, 2000a.

Freed MA. Rate of quantal excitation to a retinal ganglion cell evoked by sensory input. J Neurophysiol 83: 956-966, 2000b.

Freed MA and Sterling P. The on-alpha ganglion cell of the cat retina and its presynaptic cell types. J Neurosci 8: 2303-2320, 1988.

Geisler WS, Albrecht DG, Salvi RJ, and Saunders SS. Discrimination performance of single neurons: rate and temporal pattern information. J Neurophysiol 66: 334-362, 1991.

Hsu A, Tsukamoto Y, Smith RG, and Sterling P. Functional architecture of primate cone and rod axons. Vision Res 38: 2539-2549, 1998.

Kageyama GH and Wong-Riley MT. The histochemical localization of cytochrome oxidase in the retina and lateral geniculate nucleus of the ferret, cat, and monkey, with particular reference to retinal mosaics and ON/OFFcenter visual channels. J Neurosci 4: 2445-2459, 1984.

Kaplan E and Shapley RM. X and Y cells in the lateral geniculate nucleus of macaque monkeys. J Physiol 330: 125-143, 1982.

Kaplan E and Shapley RM. The primate retina contains two types of ganglion cells, with high and low contrast sensitivity. Proc Natl Acad Sci USA 83: 2755-2757, 1986.

Kier CK, Buchsbaum G, and Sterling P. How retinal microcircuits scale for ganglion cells of different size. J Neurosci 15: 7673-7683, 1995.
Koch K, Mclean J, Berry M, Sterling P, Balasubramanian V, and Freed M. Efficiency of information transmission by retinal ganglion cells. Curr Biol 14: 1523-1530, 2004.

Kolb H. The inner plexiform layer in the retina of the cat: electron microscopic observations. J. Neurocytol 8: 295-329, 1979.

Laughlin SB, van Steveninck RRD, and Anderson JC. The metabolic cost of neural information. Nat Neurosci 1: 36-41, 1998.

Levick WR. Receptive fields and trigger features of ganglion cells in the visual streak of the rabbit's retina. $J$ Physiol 188: 285-307, 1967.

Linsenmeier RA, Frishman LJ, Jakiela HG, and Enroth-Cugell C. Receptive field properties of $\mathrm{X}$ and $\mathrm{Y}$ cells in the cat retina derived from contrast sensitivity measurements. Vision Res 22: 1173-1183, 1982.

McCourt ME, and Jacobs GH. Spatial filter characteristics of optic nerve fibers in Calnifornia ground squirrel (Spermophilus beecheyi). J Neurophysiol 52: 1181-1199, 1984.

Merwine DK, Amthor FR, and Grzywacz NM. Interaction between center and surround in rabbit retinal ganglion cells. J Neurophysiol 73: 1547-1567, 1995.

Naka KI and Rushton WA. S-potentials from luminosity units in the retina of fish (Cyprinidae). J Physiol 185: 587-599, 1966.

O'Brien B, Isayama T, Richardson R, and Berson DM. Intrinsic physiological properties of cat retinal ganglion cells. J Physiol 538: 787-802, 2002.

Quick RF. A vector magnitude model of contrast detection. Kybernetik 16: 65-67, 1974.

Rowe MH and Cox JF. Spatial receptive-field structure of cat retinal W cells. Vis Neurosci 10: 765-779, 1993.

Rowe MH and Palmer LA. Spatial-temporal receptive-field structure of phasic W cells in the cat retina. Vis Neurosci 12: 117-139, 1994.

Shannon CE and Weaver W. The Mathematical Theory of Communication. Urbana, IL: University of Illinois Press, 1949.

Sterling P. How retinal circuits optimize the transfer of visual information. In: The Visual Neurosciences, edited by Chalupa LM and Werner JS. Cambridge, MA: MIT Press, 2004.

Stone $\mathbf{J}$ and Fukuda Y. Properties of cat retinal ganglion cells: a comparison of W-cells with X- and Y-cells. J Neurophysiol 37: 722-748, 1974.

Troy JB. Spatial contrast sensitivities of X and Y type neurons in the cat's dorsal lateral geniculate nucleus. J Physiol 344: 419-432, 1983.

Troy JB and Shou T. The receptive fields of cat retinal ganglion cells in physiological and pathological states: where we are after half a century of research. Prog Retin Eye Res 21: 263-302, 2002.

Van Hooser SD, Heimel AF, and Nelson SB. Receptive field properties of laminar organization of lateral geniculate nucleus in the gray squirrel (Sciurus carolinensis). J Neurophysiol 90: 3398-3418, 2003.

Wässle $\mathbf{H}$ and Boycott BB. Functional architecture of the mammalian retina. Physiol Rev 71: 447-480, 1991.

Watanabe M, Fukuda Y, Hsiao CF, and Ito H. Electron microscopic analysis of amacrine and bipolar cell inputs on Y-, X-, and W-cells in the cat retina. Brain Res 358: 229-240, 1985.

Weber AJ and Stanford LR. Synaptology of physiologically identified ganglion cells in the cat retina: a comparison of retinal X- and Y-cells. J Comp Neurol 343: 483-499, 1994.

Weibull W. A statistical distribution function of wide applicability. $J$ Appl Mech 18: 292-297, 1951.

Wilson PD and Stone J. Evidence of W-cell input to the cat's visual cortex via the C laminae of the lateral geniculate nucleus. Brain Res 92: 472-478, 1975. 